\title{
Incorporation of Evidence-Based Surgery into the Curriculum
}

\author{
Nilofer Husnoo ${ }^{1}$ - Judith Johnston ${ }^{1} \cdot$ Athur Harikrishnan ${ }^{1}$ (1)
}

Received: 18 May 2021 / Accepted: 9 July 2021 /Published online: 24 July 2021

(c) Association of Surgeons of India 2021

\begin{abstract}
Surgeons have historically learned their craft through the apprenticeship model from their mentors. Knowledge and practices acquired this way can rapidly become outdated. Providing high-quality care to patients requires surgeons to keep their knowledge up to date in line with evolving new evidence. The principles of evidence-based medicine (EBM) and its application to surgery, evidence-based surgery (EBS), are pivotal in updating and refining surgical practice. Changing from the conventional practice of surgical education to a structured evidence-based format requires a transformative process in all the levels of surgical practice encompassing trainees and trainers. Equally important is providing an optimal environment to review the evidence and deliver the surgical teaching and incorporate effective assessment tools to monitor the process. In this article, we revisit the levels of evidence and explore the different issues related to EBS such as barriers to EBS, incorporation of EBS to the surgical curriculum and discuss practical ways to implement EBS in the surgical curriculum.
\end{abstract}

Keywords Evidence-based medicine $\cdot$ Evidence-based surgery $\cdot$ Surgical training $\cdot$ Surgical curriculum $\cdot$ Assessment

\section{Introduction}

Surgeons have historically learned their craft through the apprenticeship model from their mentors. Knowledge and practices acquired this way can rapidly become outdated. Providing high-quality care to patients requires surgeons to keep their knowledge up to date in line with evolving research [1]. This is why every surgeon should be familiar with the principles of evidence-based medicine (EBM) and should be comfortable applying them to clinical problems.

EBM is defined as the integration of individual clinical expertise with the best available evidence from clinically relevant research, to make decisions about patient care while respecting patients' choices and values [2]. In the context of surgical practice, the term evidence-based surgery (EBS) is often used instead. EBM has been shown to lead to standardised and improved quality of care [3].

To practice EBM or EBS, physicians or surgeons should be able to perform an effective literature search to answer a clinical question, appraise the validity of the information and

Athur Harikrishnan

harikrishnan@doctors.org.uk

1 Department of Colorectal Surgery, Northern General Hospital, Sheffield Teaching Hospitals NHS Trust, Herries Road, Sheffield S10 4NH, UK use this information, in conjunction with their clinical expertise and consideration for patients' values, to guide their management of patients [1]. Levels of evidence are the key components of evaluating the validity of evidence. In 1989, Sackett consolidated the hierarchy of evidence Table 1.

Surgeons were initially slow to adopt EBM [4]. Over the years, surgical research has accounted for a much smaller percentage of published randomised controlled trials and Cochrane reviews, when compared to medical studies [4]. There is a need to train surgeons such that EBS starts to translate more effectively into surgical practice. In this article, we aim to outline the barriers to adoption of EBS and explore how it can be integrated into the surgical curriculum to overcome these barriers.

\section{Barriers to Evidence-Based Surgery}

As we identify ways in which an evidence-based curriculum may be introduced in surgery, we must first address the current barriers. The role of the surgical faculty cannot be underestimated [5]. Those at the heart of surgical curriculum setting may be unsure what evidence-based comprises, confusing it with simply 'the best way to teach something'. Faculty must be supported in their own education. Surveys have found that teachers' lack of knowledge around EBS 
Table 1 Hierarchy of evidence

\begin{tabular}{ll}
\hline Level & Type of evidence \\
\hline I & Large randomised control trial with clear cut results \\
II & Small randomised control trial with unclear results \\
III & Cohort and case control studies \\
IV & Historical cohort and case control studies \\
V & Case series; expert opinion \\
\hline
\end{tabular}

is a key hurdle in providing teaching. Often they will have received no formal training during their time in a surgical curriculum or as they move to be supervisors [6]. Information literacy is central to EBS and a skill that is poorly taught and poorly understood. This must be fully appreciated by the curriculum setter.

Surgery is perceived as a practice based in certainty. In order to set an EB curriculum, flexibility and adaptability must be embraced as EBS explores the grey areas and to do that surgeons cannot have pre-formed conceptions [7].

Surgical curricula cover a vast array of subjects and there may be a perception that there is a dearth of time in order to cover evidence-based components individually. Motivation of the learner will prove a barrier. If there is seen to be insufficient formal assessment of technique or time ascribed, then students will seek to spend time on other areas of study. From our daily surgical practice, we can see the innumerable ways in which a 'standard' procedure is actually performed, like laparoscopic cholecystectomy and endoscopic procedures like colonoscopy. This would indicate that we are not basing our daily practice on evidence. However, structured instruction with hierarchical task analysis can help teaching the same procedure with a more formal connotation.

Where competencies in evidence-based surgery have been assessed, confusion and disparity in the standards set at the yearly review of a trainee's progress have formed further barriers. [8].

Journal clubs are popular but often there is a dissonance between discussion there and implementation of evidencebased application in daily practice [9]. Studies would suggest that when EBS is so encapsulated, no or limited improvements are made. A transition to embedded practice from ad hoc teaching requires the engagement of policy makers and institutions [10]. Lack of time to read primary research and lack of access to look up evidence during direct patient care are seen by trainees as barriers to implementation of EBS [11]. Individuals will often not have the paid membership required to read primary research articles.

Following on from this is the notion of attitude. We can see from the hierarchy of evidence basis that expert opinion occupies a low level of evidence. However, as surgeons, we rely on this. Senior consultants may feel that their level of experience throughout their career bestows them with the knowledge of the right way without basing this on higher levels of evidence [12].

Surgical innovation and techniques both evolve and fall in and out of favour. This creates a high volume of trials and evidence on which to base EBS. This body of work requires constant review, which adds to the challenges of introducing EBS to a surgical curriculum.

\section{Incorporation of Evidence-Based Surgery into the Curriculum}

Although there is an increased appreciation of the importance of EBS, there still remains a gap between research and surgical practice. EBS teaching therefore needs to be delivered using various methods that aim to bridge this gap.

\section{When Should EBS be Taught?}

For surgeons to become accustomed to the application of EBM principles to clinical practice, it would seem logical that they should be encouraged to adopt it from the start of their career, which provides the rationale for EBS to be part of the undergraduate medical curriculum. The level of students' clinical maturity is likely to influence their uptake of EBS, as students who have not been exposed to the clinical environment have been reported to find EBS irrelevant [13]. However, as there is a trend towards early clinical exposure in more recent years, there may be opportunities to introduce EBS teaching sooner in the context of patient care.

\section{How Should EBS be Taught?}

A range of teaching methods delivered to undergraduate students have been described but identifying the most effective is difficult as studies evaluating these methods lack robust outcome measures [14]. Multiple exposures over time, as opposed to a single intensive course, have been linked with increased learning and improved student attitude towards EBS and its role in clinical practice $[15,16]$. Interactive and workshop-style teaching sessions have been shown to translate into improved abilities to search the literature and formulate a clinical question compared to didactic teaching [16]. Small group discussions and case scenarios are also favoured [17]. In their review article on EBS training in undergraduate students, Maggio et al. suggest that integrating EBS as a spiral curriculum (where learners have multiple, successive exposures to a concept at different levels of their development with each session building on the previous) [18], with clinical context, may be an effective model [14].

Few studies have evaluated the effectiveness of EBS techniques amongst postgraduates, but it may be appropriate to 
apply the same principles. Journal clubs are a popular means of improving surgeons' engagement with EBS. [19]. They have been shown to improve participants' critical appraisal skills, as well as the number of articles participants read per week $[19,20]$. A randomised controlled trial involving 81 Canadian surgeons demonstrated that internet-based journal clubs can also improve critical appraisal skills [21]. The same investigators compared the effectiveness of the internet-based journal club with a face-to-face moderated journal club [22]. They found that although the two groups had similar test scores, the face-to-face group engaged more than the internet group, completing more of the allocated tasks. This supports an argument for journal clubs to be part of surgical training curriculum. While face-to-face sessions led by a mentor is ideal, in the current circumstances brought on by the COVID-19 pandemic, internet-based journal clubs have been the platform of choice (a UK-based example being www.cramsurg.org).

As accessing primary research can be time-consuming, institutions and regulatory bodies should ensure that their guidelines and protocols reflect current evidence and are available at point of care. Guidelines often provide a quick and easily accessible summary of best practice. In their description of a successful programme designed to develop surgical trainees' critical appraisal skills, Haines et al. acknowledge that good access to electronic resources is vital and recognise that further technological implementation is required before resources can be accessed at the patient's bedside [12].

\section{Moving from Institution Based EBS to a National Effort}

The methods described above are dependent on the support available in individual institutions from trainers (willing to teach EBS), rota managers (allowing protected teaching time) and information providers (librarians and information technology services). Coherent national policies would allow it to be delivered in a more structured way [10].

EBS skills should be part of the core competencies in the national surgical curriculum that any surgical trainee should be expected to have demonstrated by the time their training is complete. The 'intercollegiate surgical curriculum programme' or ISCP (the approved UK framework for surgical training) requires that all trainees demonstrate use of current best evidence to make decisions about patients, and outlines a number of well-defined knowledge, skills and behaviour-based descriptors that are to be used to assess trainees' competence in this area [23]. Perhaps, another step forward would be to include more detailed outcome descriptors, such as the amount of protected EBS teaching time trainees should receive. Additionally, if national regulatory bodies and professional societies promote EBS as a means of improving patient care and cost-effectiveness [24], more concerted efforts may result, especially in terms of funding, to provide access to resources required to enable EBS to translate into practice.

Studies evaluating the teaching methods described above have not measured whether these interventions produced any effect on patient care. To ensure uptake of EBS in a meaningful way that it is reflected in clinical practice, trainees should be involved as stakeholders in EBS processes. This means that they should be involved in developing, disseminating and implementing EBS, so that they become advocates of EBS [10]. In the case of the ISCP, trainees are expected to show evidence of participation in research, authorship in peer-reviewed publications and involvement in the development of guidelines and participation in quality improvement projects (QIPs). QIPs are closely related to EBS in that they ensure correct implementation of evidencebased practices [25]. They are a simple way of involving trainees in leading evidence-based changes to practice.

\section{Training the Trainers}

An initiative by Macrae et al. demonstrated that moderated sessions led by a mentor result in more engagement by trainees [21, 22]. The current generation of surgeons should receive adequate training in using and teaching EBS to act as role models to trainees. Linking competence in applying EBS to one's practice and teaching EBS to trainers' professional accreditation processes may help to change existing attitudes.

\section{Conclusion}

Integration of EBS into the surgical curriculum will require concerted efforts by trainers, trainees, institutions and regulatory bodies. The aim is to teach EBS and its application to surgical practice in a way that will create a generation of surgeons who value EBS and propagate it to future trainees. Creating an environment for delivering EBS and providing adequate resources to do so, including time for trainees and trainers, will ensure that EBS will provide safe and effective patient care now and for generations to come.

\section{References}

1. Griffin M, Jordan DJ, El Gawad A (2016) Teaching evidence based medicine in surgical education: the challenges and techniques in training. Open Med J 3(Suppl-3, M8): 337-345

2. Sackett DL, Rosenberg WM, Gray JA, Haynes RB, Richardson WS (1996) Evidence based medicine: what it is and what it isn't. BMJ 312(7023):71-72. https://doi.org/10.1136/bmj.312.7023.71 
3. Hasnain-Wynia R (2006) Is evidence-based medicine patientcentered and is patient-centered care evidence-based? Health Serv Res 41(1):1-8. https://doi.org/10.1111/j.1475-6773.2006.00504.x

4. Meshikhes AW (2015) Evidence-based surgery: The obstacles and solutions. Int J Surg 18:159-162. https://doi.org/10.1016/j. ijsu.2015.04.071

5. Bhandari M, Montori V, Devereaux PJ, Dosanjh S, Sprague S, Guyatt GH (2003) Challenges to the practice of evidence-based medicine during residents' surgical training: a qualitative study using grounded theory. Acad Med 78(11):1183-1190. https://doi. org/10.1097/00001888-200311000-00022

6. Young T, Rohwer A, Volmink J, Clarke M (2014) What are the effects of teaching evidence-based health care (EBHC)? Overview of systematic reviews. PLoS ONE 9(1):e86706. https://doi.org/10. 1371/journal.pone.0086706

7. Maggio LA (2016) Educating physicians in evidence based medicine: current practices and curricular strategies. Perspect Med Educ 5(6):358-361. https://doi.org/10.1007/s40037-016-0301-5

8. Rangan A, Pitchford J, Williams P et al (2017) Standardisation of delivery and assessment of research training for specialty trainees based on curriculum requirements: recommendations based on a scoping review. BMJ Open 7:e013955. https://doi.org/10.1136/ bmjopen-2016-013955

9. Hatala R, Keitz SA, Wilson MC, Guyatt G (2006) Beyond journal clubs. Moving toward an integrated evidence-based medicine curriculum. J Gen Intern Med 21(5):538-541. https://doi.org/10. 1111/j.1525-1497.2006.00445.x

10. Lehane E, Leahy-Warren P, O'Riordan C, Savage E, Drennan J, O'Tuathaigh C, O'Connor M, Corrigan M, Burke F, Hayes M, Lynch H, Sahm L, Heffernan E, O'Keeffe E, Blake C, Horgan F, Hegarty J (2019) Evidence-based practice education for healthcare professions: an expert view. BMJ Evid Based Med 24(3):103-108. https://doi.org/10.1136/bmjebm-2018-111019

11. Kwaan MR, Melton GB (2012) Evidence-based medicine in surgical education. Clin Colon Rectal Surg 25(3):151-155. https://doi. org $/ 10.1055 / \mathrm{s}-0032-1322552$

12. Haines SJ, Nicholas JS (2003) Teaching evidence-based medicine to surgical subspecialty residents. J Am Coll Surg 197(2):285289. https://doi.org/10.1016/S1072-7515(03)00114-5

13. Astin J, Jenkins T, Moore L (2002) Medical students' perspective on the teaching of medical statistics in the undergraduate medical curriculum. Stat Med 21(7):1003-6; discussion 1007. https://doi. org/10.1002/sim.1132

14. Maggio LA, Tannery NH, Chen HC, ten Cate O, O'Brien B (2013) Evidence-based medicine training in undergraduate medical education: a review and critique of the literature published 2006-2011. Acad Med 88(7):1022-1028. https://doi.org/10.1097/ ACM.0b013e3182951959

15. Norman G (2009) The American College of Chest Physicians evidence-based educational guidelines for continuing medical education interventions: a critical review of evidence-based educational guidelines. Chest 135(3):834-837. https://doi.org/10.1378/chest. 09-0036

16. Kotur PF (2012) Introduction of evidence-based medicine in undergraduate medical curriculum for development of professional competencies in medical students. Curr Opin Anaesthesiol 25(6):719-723. https://doi.org/10.1097/ACO.0b013e32835a1112

17. Liabsuetrakul T, Sirirak T, Boonyapipat S, Pornsawat P (2013) Effect of continuous education for evidence-based medicine practice on knowledge, attitudes and skills of medical students. J Eval Clin Pract 19(4):607-611. https://doi.org/10.1111/j.1365-2753. 2012.01828.x

18. Bruner JS (1963) The Process of Education. Vintage Books, New York

19. Ahmadi N, McKenzie ME, Maclean A, Brown CJ, Mastracci T, McLeod RS; Evidence-Based Reviews in Surgery Steering Group (2012) Teaching evidence based medicine to surgery residents-is journal club the best format? A systematic review of the literature. J Surg Educ 69(1):91-100. https://doi.org/10.1016/j.jsurg.2011. 07.004

20. Khan KS, Dwarakanath LS, Pakkal M, Brace V, Awonuga A (1999) Postgraduate journal club as a means of promoting evidence-based obstetrics and gynaecology. J Obstet Gynaecol 19(3):231-234. https://doi.org/10.1080/01443619964968

21. Macrae HM, Regehr G, McKenzie M, Henteleff H, Taylor M, Barkun J, Fitzgerald GW, Hill A, Richard C, Webber EM, McLeod RS (2004) Teaching practicing surgeons critical appraisal skills with an Internet-based journal club: A randomized, controlled trial. Surgery 136(3):641-646. https://doi.org/10.1016/j.surg. 2004.02.003

22. McLeod RS, MacRae HM, McKenzie ME, Victor JC, Brasel KJ; Evidence Based Reviews in Surgery Steering Committee (2010) A moderated journal club is more effective than an Internet journal club in teaching critical appraisal skills: results of a multicenter randomized controlled trial. J Am Coll Surg 211(6):769-76. https://doi.org/10.1016/j.jamcollsurg.2010.08.016

23. Intercollegiate Surgical Curriculum Programme. The syllabus [Internet].. United Kingdom: JCST [updated 2020; cited 2021 Apr 15].. Available from: https://www.iscp.ac.uk/curriculum/surgical/ surgical_syllabus_list.aspx

24. Meakins JL (2006) Evidence-based surgery. Surg Clin North Am 86(1):1-16, vii. https://doi.org/10.1016/j.suc.2005.10.004

25. Glasziou P, Ogrinc G, Goodman S (2011) Can evidence-based medicine and clinical quality improvement learn from each other? BMJ Qual Saf 20:i13-i17

Publisher's Note Springer Nature remains neutral with regard to jurisdictional claims in published maps and institutional affiliations. 